\title{
ANÁLISE DA QULIDADE DOS SERVIÇOS EDUCACIONAIS PRESTADOS NA EDUCAÇÃO INFANTIL DE ACORDO COM A EXPECTATIVA DOS GESTORES, PROFESORES E PAIS
}

Irene Antônia de Moura ${ }^{1}$; Adriana dos Santos Prado Sadoyama²; Geraldo Leal Sadoyama

\section{Resumo}

As constantes mudanças e evoluções sociais tem levado o consumidor a ficar cada vez mais exigente com relação à qualidade dos serviços prestados, principalmente na área educacional. Fator que tem contribuído para que as pessoas procurem instituições de ensino que ofereçam esses serviços com qualidade. Analisando esse contexto foi realizada uma pesquisa cujo objetivo é mensurar e discutir a qualidade dos serviços educacionais ofertados na Educação infantil de acordo com a expectativa e a percepção dos gestores, professores e pais da Coordenação Regional de Ensino do Núcleo Bandeirante do Distrito Federal. Trata-se de uma de pesquisa com abordagem quantitativa, descritiva, exploratória, explicativa, transversal, bibliográfica e documental, teórica e aplicada. Foram descritos os dispositivos legais que garantem e norteiam uma escola de qualidade; definição de serviços, qualidade em serviços, serviços educacionais, expectativa e percepção. Para realizar a coleta de dados foi utilizada a escala SERVQUAL, instrumento elaborado por três pesquisadores norte americanos para mensurar a qualidade em serviços. Para esta pesquisa

1 - Mestranda no curso de Gestão Organizacional pela Universidade Federal de Goiás. Campus Catalão. irene.antoniademoura@gmail.com

2 - Docente da Universidade Federal de Goiás - Regional de Catalão. Professora do Mestrado profissional em Gestão Organizacional. Doutora em Letras e formação em Pedagogia. drisadoyama@gmail.com.

3 - Docente da Universidade Federal de Goiás - Regional de Catalão. Professor do Mestrado Profissional em Gestão Organizacional. Doutor em Imunologia e Parasitologia aplicadas.gsadoyama@gmail.com. 
na área educacional a escala foi adaptada de acordo com um documento denominado Indicadores da Qualidade na Educação Infantil. Com este projeto de pesquisa espera-se que os resultados alcançados auxiliem os grupos envolvidos a desenvolver um trabalho pedagógico eficaz e preciso com o intuito de melhorar o setor que mais necessita de atenção, e assim prestar serviços educacionais de qualidade.

Palavras Chave: Percepção. Expectativa. Qualidade em serviços educacionais. 